\title{
Analysis and Management of Academic Procrastination Behavior of Students with Internet Addiction
}

\author{
Zhe $\mathrm{Ti}^{1}$, Li Zhang ${ }^{2, *}$ and Jin Yan ${ }^{2}$ \\ ${ }^{1}$ The Subsidiary Experimental School of the Northeast Normal University, Changchun, Jilin, 130117, China \\ ${ }^{2}$ International Business School, Jilin International Studies University, Changchun, Jilin, 130012, China \\ *Corresponding author.Email: zhangli2021@jisu.edu.cn
}

\begin{abstract}
Internet addiction is a behavioral manifestation of excessive use of mobile phones, computers, and other electronic devices to use the Internet, which can lead to impaired social functions and bring psychological and behavioral problems to a new type of behavioral addiction. Academic procrastination is a phenomenon in which learners generally and persistently desire to postpone their studies, accompanied by anxiety. There is a clear positive correlation between the degree of students' Internet addiction and the degree of academic procrastination, and time management ability and learning efficacy play a role in the influence of students' Internet addiction on their academic procrastination behavior. At present, the detection rate of academic procrastination remains high among the student population. Internet dependence can significantly affect academic procrastination and is an important risk factor for academic procrastination. Starting from the influence mechanism of network dependence and academic procrastination, this paper uses incentive theories such as two-factor theory, goal-setting theory, and expectation theory to improve students' time management ability and learning efficacy and other potential mechanisms to alleviate network dependence, and put forward suggestions for academic procrastination. Governance recommendations.
\end{abstract}

Keywords: Internet addiction, academic procrastination, motivation, learning efficacy

\section{INTRODUCTION}

Internet addiction and academic procrastination are common problems in school education at present, which seriously affect the quality of teaching. For students who are not fully mature in terms of cognition and psychology, Internet addiction has caused serious damage to their physical and mental health and study life and directly affects the learning effect. Studies have shown that the current proportion of Chinese students' Internet addiction is extremely high, and academic delays are also very serious, which has greatly affected the improvement of the quality of education and teaching. An important task of education is to cultivate students' self-management and learning abilities. Therefore, it is not possible to simply adopt the teaching management methods such as strengthening supervision to treat the symptoms but not the root cause. It is necessary to analyze the cognitive mechanisms and influence paths of Internet addiction and academic delays. Starting from the problem and combining the characteristics of students' psychological needs, design a practical and feasible comprehensive treatment plan.

\section{RELATED CONCEPTS AND THEORETICAL BASIS}

The concept of Internet addiction was first proposed by Goldberg in 1996. It refers to a phenomenon in which a person uses the Internet for a long time and continuously, which causes harm to the individual's society, psychology, and body. There are many classifications of internet addiction, such as internet game addiction, internet information collection addiction, internet relationship addiction, internet gambling addiction, internet shopping addiction, etc. Internet addiction can have many negative effects on individuals, such as social withdrawal, weariness or truancy, depression, loneliness, etc. Phenomenon[1]. Solomon and Rothblum (1984)[2] proposed the concept of academic procrastination. This study believes that academic procrastination is caused by the imbalance between the individual's intention and behavior in the three dimensions of cognition, behavior, and emotion under the condition of subjective willingness and actual behavior obstacles, or even completely evades the learning tasks they must undertake. The tendency of behavioral choice.

\subsection{Related Theories of Internet Addiction}

Tao Ran (2019) uses three motivational theories to explain the psychological mechanism of Internet addiction[3]. First 
of all, the first theory applied is Masnow's demand theory. With the continuous progress of society, the low-level needs of most students in China, such as survival and safety needs, have basically been met. Therefore, for most students nowadays, high-level needs such as social needs, respect needs, and self-fulfillment needs are more urgently needed to be met. In choosing the path to fulfill their needs, some students will set foot on the Internet, become obsessed with the Internet, and even become addicted to the Internet. The principle of the second explanation mechanism applies to Erickson's eight-stage theory. The key stage for students to develop self-awareness is the conflict stage between the ideal self and the real self. Therefore, it is easier to indirectly use the ideal self to measure the real self. At this time, the virtual nature of the network just meets the needs of realizing the students' ideal selves. The principle of the third explanation mechanism is the tree of life theory. The individual's emotional needs are the root, and other needs are the tree trunk. Students' emotional needs are not met, that is, when the roots are not met, the tree trunk will not have sufficient nutrients to grow, and students cannot actively cope with the difficulties in life. Can only use virtual networks to meet their emotional needs.

\subsection{Related Theories of Academic Procrastination}

Academic procrastination is a common problem in current school education and family education. The heavy academic pressure requires students to have strong selfstudy ability, time management ability, and self-control. Most students have experienced academic procrastination, and the degree of student procrastination will also change in the face of different academic tasks.

Academic procrastination is caused by the mutual influence of multiple factors from the inner body, mind, and body to the external environment, which are mainly manifested in behavioral cognitive tendencies, psychological characteristics, personality traits, and external factors. Studies have found that low selfconfidence, distracted attention, perfectionist tendencies, negative emotions, and low learning motivation are all causes of academic delays. Robert (2012) believes that the degree of student procrastination is directly related to the student's time management ability[4]. The higher the time management ability, the lower the degree of academic delay. If students have high self-control ability, they can complete their study work in an orderly manner and allocate entertainment time reasonably, thereby reducing the level of academic procrastination. However, if the student's self-control ability is low, then it is easy to be attracted by external things in the learning process, which will lead to the phenomenon of academic delay.

\section{THE IMPACT OF STUDENTS' INTERNET ADDICTION ON ACADEMIC PROCRASTINATION}

Internet addiction can induce procrastination behavior because Internet addiction can induce negative emotions, increase the individual's excessive desire for the Internet, and reduce the individual's resistance to Internet temptation, leading to individual procrastination behavior. Valeria (2017) research shows that the degree of academic procrastination and time management ability of students is closely related to the degree of dependence on the Internet[5]. If the student's time management ability is high, the degree of academic delay will be reduced, and if the student's dependence on the Internet is high, the degree of academic delay will also increase.

Studies have shown that Internet addiction is significantly positively correlated with negative emotions such as anxiety and depression. Internet addiction can negatively affect learning efficacy, and learning efficacy will negatively affect academic procrastination. Learning efficacy refers to students' prediction of the level of learning that they can achieve and how to solve related learning problems. It also includes the evaluation of their own learning ability. In addition, emotion is also one of the important factors that affect learning efficacy. Internet addiction can destroy the ability of emotional self-control, and then induce negative emotions.

\section{MEASURES TO CONTROL THE BEHAVIOR OF STUDENTS WITH INTERNET ADDICTION}

The research on the relationship between students' Internet addiction and academic procrastination began in psychology. With the gradual deepening of the research, scholars from different disciplines such as sociology, pedagogy, and behavior have also joined the research on this issue. Failed to come up with a fundamental solution. Therefore, it is necessary to fully learn from the research results of various disciplines, combine the methods of pedagogy and management, conduct in-depth research on this problem, and use the incentive theory in management to propose a more operational comprehensive solution. 


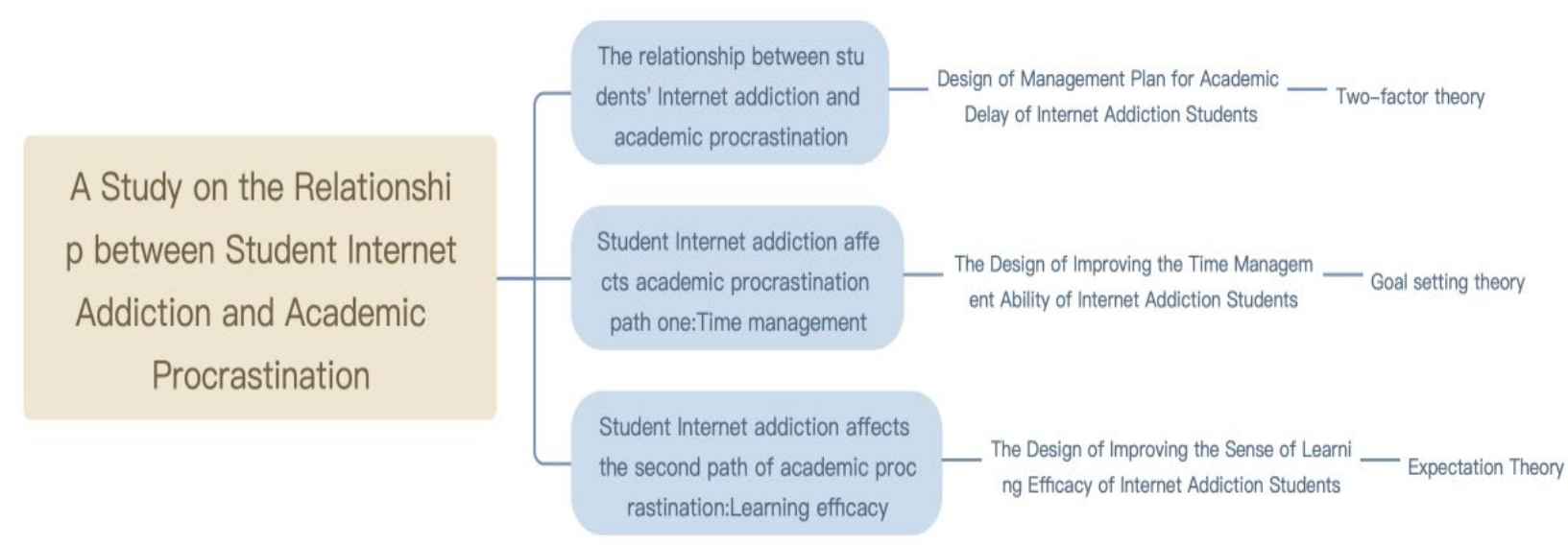

Figure 1. The relationship between the behaviors of students with internet addiction disorder and the management measures

\subsection{Use the Two-Factor Theory to Control the Academic Procrastination Behavior of Internet Addiction Students}

In the 1950s, the American management psychologist Herzberger proposed the two-factor theory, that is, the "health-incentive" theory[6]. This theory also has applicable value to education management in the field of pedagogy. He believes that the external working environment can maintain the enthusiasm of members and eliminate dissatisfaction, so he called it a health care factor. Intrinsic factors refer to those factors that can stimulate work enthusiasm and improve work efficiency, so they are called motivating factors. Student management is systemic management based on human-centeredness. The two-factor theory also focuses on human development. Interpersonal communication is an important way to cultivate students' intimacy. An interpersonal relationship is also the main source of students' psychological problems and conflicts. Therefore, it is necessary to help students establish a correct concept of interpersonal communication between teachers and students and between students. On the one hand, starting from health care factors, for the good development of students, we should consider creating an inclusive and positive growth environment for them; on the other hand, starting from incentive factors, in order to improve the overall quality of students and encourage the development of student's personality, it can fully mobilize students' Autonomy and creativity reduce academic procrastination.

\subsection{Use Goal-Setting Theory to Control the Academic Procrastination Behavior of Internet Addiction Students}

The goal-setting theory was first proposed by American managerial psychology professor Locke in 1967. He believed that the goal itself contained motivation. Goalsetting theory is of great significance for improving students' time management ability and paying attention to setting goals[7]. First of all, based on this theory, education administrators should participate in goal setting with students, which can increase students' enthusiasm in the process of achieving goals, and at the same time improve the authenticity and achievability of the set goals, and ultimately strengthen students' self-confidence. In addition, in order to help students understand the meaning of time management, education administrators can set a big goal for students that requires long-term hard work and completes several phased goals. The interim goals must be challenging to arouse students' motivation and enthusiasm so that students can gradually achieve the big goals in the process of facing pressure and solving difficulties. Schools should appropriately use different incentives to exercise students' time management ability, stimulate students' learning autonomy and continuity so that students have balanced and comprehensive development in all aspects of learning and life.

\subsection{Use Expectation Theory to Control the Academic Procrastination Behavior of Internet Addiction Students}

In 1964, Victor Froome, a scientist in the field of behavioral science and psychology, multiplied the expected value of completing the task by the valence of incentives in 
his book "Work and Incentive", and believed that the result would directly affect the degree to which people's enthusiasm was mobilized[8]. In other words, the higher the degree of individual control over the goal, the greater the probability of achieving the goal. Based on this theory, in student management, it is necessary to actively accept the instructive role of expectation theory in the motivational role, and implement reliable assessments of student behavior. At present, using expectation theory to improve learning interest, students' learning autonomy and self-management ability have been maximized. Therefore, in student management, the most important thing is to improve students' self-consciousness and strengthen their sense of learning efficacy and use effective incentive measures to help students integrate into class learning. In a harmonious and active learning environment, students will be easier to self-manage, stimulate strong interest in learning and reduce their attention to the Internet. Only by effectively establishing a reward and punishment mechanism based on the real situation can the motivational effect of expectation theory be better applied to students. Teachers should provide students with comprehensive and multi-angle understanding and support, create an atmosphere of diligent learning, and form a highly selfcontrolled learning Environment to avoid academic delays.

\section{CONCLUSION}

At present, Internet dependence is the main cause of academic delays, and the academic delays of student groups are more serious. Students are exposed to the Internet. In the future, with the promotion of $5 \mathrm{G}$ technology and the advancement of online teaching reforms and other factors, the frequency of Internet use will continue to increase. It is a very meaningful study to reduce the harm of Internet dependence to student groups. Therefore, it is necessary to start from the influence mechanism of network dependence and academic procrastination, through the two-factor theory, goal-setting theory, and expectation theory, and other incentive theories, and improve students' time management ability and learning efficacy and other potential mechanisms to alleviate the influence of network dependence on academic work. The impact of procrastination.

\section{ACKNOWLEDGMENT}

Fund item: 2021 degree key item of Research Project From Jilin Association for Higher Education "Research on the relationship between Internet addiction and academic procrastination of College Students" item number: JGJX2021C49

\section{REFERENCES}

[1] Goldberg K., Masha M., Gentner S., et al. Desktop teleoperation via the world wide web//IEEE. Robotics and Automation, Nagoya: IEEE, 1995:654-659.

[2] Solomon L. J., Rothblum1 E. D. Academic procrastination: frequency and cognitive behavioral correlates[J]. J Counse Psychol, 1984(04):503-509.

[3] Ran Tao. Analysis and intervention of Internet addiction [J]. Psychology and Health, 2019(07): 2224.In Chinese

[4] Maccann, C., G. J. Fogarty, and R. D. Robert. "strategies for success in education: Time management is more important for part-time than full-time community college student." Learning and Individual Differences (2012).

[5] Valeria D P, Lucia M, Silvana M, et al. Decisional Procrastination in Academic Settings: The Role of Metacognition ns and Learning Strategies[J]. Frontiers in Psychology, 2017, 8:973.

[6] Herzberg, F. Mausner, B. \& Snyderman, B. The motivation to work[M]. New York, NY: John Wiley, 1959

[7] Locke E A, Latham G P. A Theory of Goal Setting $\&$ Task Performance[J]. The Academy of Management Review, 1991, 16(2).

[8] Vroom V H. Work and Motivation[J]. industrial organization theory \& practice, 1964. 